\title{
Functional MRI Study of Verbal Fluency in a Patient with Subcortical Laminar Heterotopia
}

\author{
Daniel L. Keene, Janet Olds, William J. Logan
}

\begin{abstract}
Rationale: Double cortex syndrome is a malformation in which there is a band of subcortical heterotopic grey matter separated from the cortex by white matter. The functional activity of the heterotopic neurons is unclear. Patient: A 13-year-old female was evaluated for seizures. The EEG showed bifrontal spike wave disturbance. Band heterotopia, in association with mild reduction of sulcation of the cerebral hemispheres, was found on MRI. Psychological assessment indicated the presence of variable cognitive abilities, with verbal IQ [82] generally better than nonverbal IQ [59], and specific difficulties in language comprehension and mathematics. Method: Functional MRI was used to localize the areas of language and motor activation. The language activation paradigm was a visual verb generation task with a visual fixation baseline. The motor paradigm consisted of alternating blocks of sequential finger tapping and rest. Coronal functional and anatomical images were obtained. Results: The motor paradigm produced activation of the primary motor cortex, the band heterotopia and the supplementary motor cortex. The language paradigm produced activation of the left inferior frontal gyrus and left supplementary motor area, but not of the band heterotopia. Conclusions: The activation of heterotopic grey matter during a motor task demonstrates a hemodynamic association with motor activity and suggests that this tissue may be functional. Such association was not seen with the language task. We speculate that later maturing functions such as language are restricted in their development to the normal situated superficial cortex in our patient.
\end{abstract}

RÉSUMÉ: Étude parIRM fonctionnelle de la facilité de parole chez un patient atteint d'hétérotopie laminaire sous-corticale. Contexte: Le syndrome du double cortex est une malformation dans laquelle il y a une bande de substance grise hétérotope sous-corticale séparée du cortex par de la substance blanche. L'activité fonctionnelle des neurones hétérotopes est mal connue. Observation: Il s'agit d'une jeune fille de treize ans, évaluée pour des crises épileptiques, qui présentait à l'ÉEG des décharges pointe-onde. L'IRM a montré une bande hétérotope associée à une légère diminution des sillons des hémisphères cérébraux. L'évaluation psychologique a montré la présence de capacités cognitives variables, le QI verbal (82) étant en général meilleur que le non verbal (59), ainsi que des problèmes dans la compréhension du langage et les opérations mathématiques. Méthodes: On a eu recours à l'IRM fonctionnelle pour localiser les zones de l'activation langagière et motrice. Le paradigme de l'activation langagière était le visual verb generation task with a visual fixation baseline. Le paradigme d'activation motrice consistait à alterner des blocs de tapping séquentiel des doigts et des blocs de repos. Des images coronales fonctionnelles et anatomiques ont été acquises. Résultats: Le paradigme moteur a provoqué une activation du cortex moteur primaire, de la bande hétérotope et du cortex moteur supplémentaire. Le paradigme langagier a provoqué une activation du gyrus frontal inférieur gauche et de l'aire motrice supplémentaire gauche, sans activation de la bande hétérotope. Conclusions: Il existe une association hémodynamique entre l'activation de la substance grise hétérotope pendant une tâche motrice et l'activité motrice, ce qui suggère que ce tissu puisse être fonctionnel. Une telle association n'a pas été observée pendant l'épreuve langagière. Nous pensons que les fonctions qui se développent plus tardivement comme le langage sont localisées uniquement à la région normale du cortex superficiel chez notre patiente.

Can. J. Neurol. Sci. 2004; 31: 261-264

The syndrome of subcortical band heterotopia or "double cortex" has been well-described in the literature. Clinically, it has been associated with epilepsy and some degree of cognitive impairment, although intellectual functioning within the average range has been reported. ${ }^{1}$ Band heterotopia usually occurs in females, although it has been reported to occur sporadically in
From the Division of Neurology, Department of Pediatrics (DLK); Neurocognitive Program, Mental Health (JO, WJL); Children's Hospital of Eastern Ontario, Ottawa,Ontario and Division of Neurology, Department of Pediatrics, Hospital for Sick Children, Toronto, Ontario, Canada.

ReCEIVED March 28, 2003. ACCePted infinalform OCtober 14, 2003. Reprint requests to: Daniel L. Keene, Division of Neurology, Department of Pediatrics, Children's Hospital of Eastern Ontario, 401 Smyth Road, Ottawa, Ontario, Canada K1H 8L1 
males. Typically, MRI shows bilateral extensive plates of heterotopic grey matter beneath the cortex that are usually more predominant anteriorly. The size and distribution of the band has been correlated with neurological status, and indirectly, to the degree of cognitive impairment. ${ }^{2}$

The band heterotopia is believed to represent a migrational arrest during the critical phase of brain development that occurs as the neurons are migrating along specialized radial glial fibers to form the six layered neocortex. Histologically it consists primarily of small pyramidal cells randomly arranged in the outer segment and columnar organization in the inner segment of the band. The cortex overlying the band in most cases has a normal six layered cortex. The participation of the heterotopic neuronal tissue in physiological cerebral functions has been demonstrated. Morrell et al, ${ }^{3}$ using depth electrodes at the time of surgery in a patient with "the double cortex syndrome" demonstrated similar epileptic patterns from the cortical and adjacent subcortical laminar neurons; as well as independent epileptiform activity arising from the subcortical laminar neurons. Positron emission tomography has been reported to show similar or even increased levels of glucose uptake in the subcortical laminar neurons in comparison to the cortical neurons. ${ }^{4,5}$ Its role in higher cerebral functions remains unclear.

Functional MRI (fMRI) has been shown to be a reliable method for examining the motor and language functions of the brain. We report the results of our fMRI study of these tasks in a patient with subcortical band heterotopia.

\section{Patient}

A 13-year-old right-handed female presented at the age of 10 years with a history of several years of recurrent attacks on waking. These attacks had been occurring about once every four months. At the time of presentation, the attacks were stereotypic. The patient would wake in the morning with an unsteady gait and having difficulty manipulating objects with her hands. Her parents had noted that during these attacks she appeared dazed. Typically, she would fall asleep within minutes and awaken fifteen minutes later with a severe pulsatile headache not associated with nausea, vomiting, photophobia, or phonophobia. The headache would usually resolve within a few hours. On the day of presentation the mother noted that the patient's attack was associated with a brief episode rhythmical jerking of the right facial muscles. The EEG showed bursts of bifrontal spikes and slow waves. An MRI demonstrated the extensive band of subcortical heterotopic grey matter.

She was started on valproate with a significant reduction in her seizure frequency. At the time of the fMRI and psychological testing the patient had been seizure free on valproate for several months.

\section{NEUROCOGNITIVEASSESSMENT}

Neurocognitive assessment suggested that intellectual functioning (WISC-III) ${ }^{6}$ was within the mildly delayed range $[\mathrm{IQ}=69]$ and adaptive behaviour ${ }^{7}$ within the borderline range (composite score $=75$ ). However, a significant difference between verbal and nonverbal abilities was also noted. This was demonstrated both on measures of intelligence, where the verbal IQ [82] was significantly higher than performance, or nonverbal
Table: A summary of patient's psychological profile

\begin{tabular}{|c|c|c|c|}
\hline \multicolumn{4}{|c|}{ Intellectual and adaptive functioning } \\
\hline \multicolumn{3}{|c|}{ Adaptive functioning $(\mathrm{ABAS})^{7}$} & 76 \\
\hline \multicolumn{3}{|l|}{ Full scale IQ (WISC III) ${ }^{6}$} & 69 \\
\hline \multicolumn{3}{|l|}{ Verbal (performance) IQ } & 82 \\
\hline \multicolumn{2}{|c|}{ Verbal Comprehension } & 83 & \\
\hline \multirow{2}{*}{\multicolumn{2}{|c|}{ Freedom from Distractibility }} & 81 & \\
\hline & & & 59 \\
\hline \multicolumn{2}{|c|}{ Perceptual Organization } & 59 & \\
\hline \multicolumn{2}{|c|}{ Processing Speed } & 77 & \\
\hline \multicolumn{4}{|l|}{ Language } \\
\hline \multicolumn{4}{|l|}{ Comprehension } \\
\hline \multicolumn{3}{|c|}{ Receptive Vocabulary (PPVT-III) ${ }^{10}$} & 97 \\
\hline \multicolumn{3}{|c|}{ Ambiguous Sentences (TLC) ${ }^{2}$} & 75 \\
\hline \multicolumn{3}{|c|}{ Listening Comprehension (TLC) ${ }^{2}$} & 85 \\
\hline \multicolumn{3}{|c|}{ Figurative Language (TLC) ${ }^{3}$} & 80 \\
\hline \multicolumn{4}{|c|}{ Expressive } \\
\hline \multicolumn{3}{|c|}{ Oral Expression (TLC) ${ }^{3}$} & 100 \\
\hline \multicolumn{3}{|c|}{ Oral Expression (WIAT) } & 119 \\
\hline \multicolumn{4}{|c|}{ Word Fluency (two minutes) ${ }^{3}$} \\
\hline \multicolumn{3}{|c|}{ Semantic (animals, food/drink) } & 12 words \\
\hline \multicolumn{3}{|c|}{ Phonetic ('s', 'f') } & 6 words \\
\hline \multicolumn{4}{|l|}{ Memory } \\
\hline \multicolumn{3}{|l|}{ Verbal $(\mathrm{CMS})^{8}$} & 75 \\
\hline \multicolumn{3}{|l|}{ Visual $(\mathrm{CMS})^{8}$} & 78 \\
\hline \multicolumn{3}{|l|}{ Learning $(\mathrm{CMS})^{8}$} & 75 \\
\hline \multicolumn{4}{|l|}{ Academic functioning } \\
\hline \multicolumn{3}{|l|}{ Reading: word (WIAT) } & 89 \\
\hline Spelling (WIAT) & & & 107 \\
\hline Comprehension -Text & WIAT) & & 90 \\
\hline Comprehension (Nelsc & -Denny) ${ }^{3}$ & & $<70$ \\
\hline Mathematic reasoning & WIAT) & & 77 \\
\hline Mathematic computati & n (WIAT) & & 79 \\
\hline Motorand Visual Motor Fu & ctioning & & \\
\hline Visual Motor Integrati & & & 78 \\
\hline Pegboard (time) & right hand & & $\mathrm{z}=3.79$ \\
\hline & left hand & & $\mathrm{z}=+7.92$ \\
\hline Tapping & right hand & & $\mathrm{z}=-1.70$ \\
\hline & left hand & & $\mathrm{Z}=-0.81$ \\
\hline Strength (dynemeter) & right hand & & $\mathrm{z}=0.24$ \\
\hline & left hand & & $\mathrm{z}=-0.81$ \\
\hline
\end{tabular}

1 Standard scores presented unless otherwise noted

2 To facilitate comparison, standard scores have been converted to $\mathrm{X}=100, \mathrm{SD}=15$

${ }^{3}$ For 12-year-old patient, score is less than first percentile

ABAS = Adaptive Beahviour Assessment System; TLC $=$ Test of Language Competence; WIAT $=$ Wechsler Individual Achievement Test; WISC $=$ Wechsler Intelligence Scale for Children; PPVT = Peabody Picture Vocabulary Test; CMS = Children's Memory Scale 


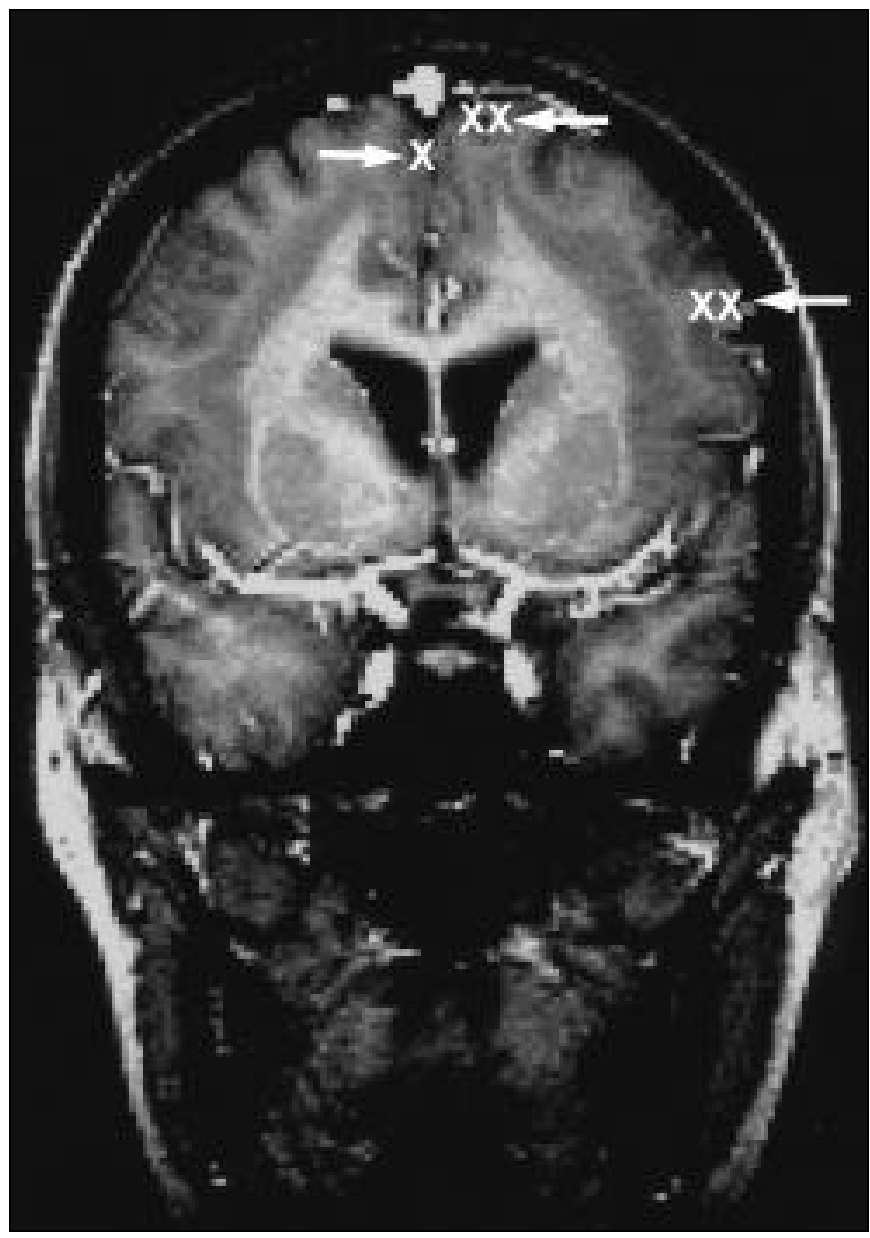

Figure: A coronal image of fMRI activation during language task demonstrating significant increase in signal intensity in the outer "normal" left inferior frontal gyrus and left supplementary motor area (as marked in with arrows and X).

IQ [59] $(\mathrm{p}<.05)$, particularly on measures of perceptualorganizational ability. Similarly, assessment of memory with the Children's Memory Scale ${ }^{8}$ indicated that visual, but not verbal, memory was significantly lower than predicted on the basis of full scale IQ and verbal IQ; a pattern of higher verbal than visual memory scores was noted on the Wide Range Assessment of Memory and Learning. ${ }^{9}$

Despite stronger verbal abilities, specific areas of difficulty were noted in complex aspects of language comprehension and expressive language. While receptive vocabulary was a strength, ${ }^{10}$ specific areas of difficulty in language comprehension were demonstrated. This was noted in her difficulty in processing sentences with multiple meanings, understanding figurative language, and making inferences (Test of Language Competence). ${ }^{11}$ While her expressive language abilities were at, or above, average when describing pictures or writing composition (Wechsler Individual Achievement Test (WIAT) ${ }^{12}$ ), when retrieving items from specific semantic or phonetic categories, reduced verbal fluency was obtained. Academically, mathematical abilities were an area of weakness. Reading comprehension abilities were weak on complex material with multiple choice questions, although there was less evidence of difficulty when reading short passages with specific probe questions (WIAT).

Performance on motor tasks, most notably grip strength and finger tapping, was within the average range, while performance on a grooved pegboard task was markedly impaired for both right (dominant) and left hands. Performance on Visual Motor Integration, as measured on a copying task, was delayed (7th percentile) ${ }^{13}$ (see the Table).

\section{fMRI STUDY}

Images were obtained using a 1.5T Signa GE Medical Systems clinical MR scanner equipped with Echospeed gradient system. A spiral $\mathrm{T} 2 *$ weighted scanning protocol $(\mathrm{TE}=40 \mathrm{~ms}$, $\mathrm{TR}=800 \mathrm{~ms}, \mathrm{FOV}=30 \mathrm{~cm}$ ) was used to image ten consecutive $7 \mathrm{~mm}$ coronal slices. Coronal high resolution T1-weighted anatomical images were obtained at identical slice locations using a rf-spoiled gradient echo sequence $\left(\mathrm{TR} / \mathrm{TR} / \mathrm{a}=50 / 6 / 45^{\circ}\right.$ flow compensation).

To study language function, the patient was asked to generate one or more verbs which could be associated with visually presented concrete nouns. Five nouns were presented per task block at a rate of five seconds per noun. The control task consisted of visual fixation on a central cross-hair flanked by a varying number of asterisks. Ten repetitions of generationfixation task cycles occurred during the scanning time.

Motor function was studied by asking the patient to do sequential finger tapping for twenty seconds alternating with twenty seconds of rest over a six minute scanning time.

The fMRI data were processed using the Stimulate data analysis program using correlation analysis. ${ }^{14}$ Pixels showing a significant difference in image intensity during the task were identified and those above a calculated threshold value were color-coded and displayed on the high resolution images.

Alternate finger tapping fMRI paradigm produced activation of the primary motor cortex, supplementary motor cortex and the underlying subcortical band heterotopia. In contrast the language activation paradigm produced activation of the left inferior frontal gyrus and left supplementary motor area. It did not produce activation in the underlying subcortical band heterotopia. (Figure)

\section{Discussion}

We present an adolescent female diagnosed with band heterotopia and seizures. Assessment of her neurocognitive functioning indicated low average verbal intelligence and significantly lower nonverbal abilities. A similar pattern of better verbal than visual functioning in memory was also documented. Despite better verbal abilities generally, selective difficulties were noted in comprehension. Academically, particular difficulties in mathematics were documented, as well as difficulties in complex dimensions of reading comprehension. Such a pattern of cognitive functioning has not been reported in the literature. While reports of band heterotopia in the literature have suggested either delayed or variable cognitive functioning, 
these reports are limited by the inclusion of a single index of intelligence or developmental status. Other dimensions of neurocognitive functioning have not been reported, and may provide important descriptive information. In addition, in exploring functional activity in selected individuals with rare developmental conditions, it is important to provide normreference indices of abilities examined in fMRI paradigms.

The fMRI tasks used in our study of this patient have been well-reported in the literature. ${ }^{15-22}$ The areas of activation seen using fMRI finger tapping paradigm have been shown to correlate well with the areas found at the time of intra-operative mapping of the primary motor strip. ${ }^{19}$ The language paradigm used in our study has been shown to correlate well with the area of language function as mapped by electrocortical stimulation at the time of surgery. ${ }^{15-22}$

The finding of fMRI activation of both the cortical and laminar neuronal layer during repeated finger tapping that occurred in our patient was similar to that which had been previously reported in five other patients. ${ }^{15-17}$ Our study was the first study which attempted to use fMRI language task to examine function of the subcortical laminar band. The reason for the activation of the cortical neurons and not the neurons located in subcortical laminar band during the language task remains speculative. It may be related to the distinct neuronal circuitries involved in each of the tasks. The motor task involves the primary motor cortex and its thalamic connections. Language tasks involve more complex networks of $U$ fibers between the associative cortex of the frontotemporal regions.

It could be hypothesized that both the subcortical laminar neurons and the cortical neurons play a role in repetitive motor activity in patients with band heterotopia.

The lack of fMRI activation of the subcortical laminar heterotopic band during the language task suggests that the neurons located in the subcortical laminar band may not be involved in language functions in our patient. This is indirectly supported by the finding of Barkovitch et $\mathrm{al}^{2}$ that there was a correlation between the size and distribution of the band and neurological status, and indirectly with level of intellectual functioning. However, investigation of cognitive functioning associated with band heterotopia has been limited to intellectual and developmental status. The relationship of cognitive abilities, as measured by standardized tests, and functional status, as measured by fMRI, is an important area for future investigation.

\section{REFERENCES}

1. Ianetti $\mathrm{P}$, Raucci $\mathrm{U}$, Basile $\mathrm{A}$, et al. Neuronal migrational disorders: diffuse cortical dysplasia or 'double cortex' syndrome. Acta Paediatrica 1993;82:501-503.
2. Barkovitch AJ, Guerrini R, Battaglia G, et al. Band heterotopia: correlation of outcome with magnetic resonance imaging parameters. Ann Neurol 1994;36:609-617.

3. Morrell F, Whisler T, Hoeppner T. Electrophysiology of heterotopic gray matter in the "double cortex" syndrome. Epilepsia 1992;33(S3):77 (abstract).

4. de Volder A, Gadisseux J-F, Michel C, Maloteaux JM, Bol AC. Brain glucose utilization in band heterotopia: synaptic activity of "double cortex". Pediatr Neurol 1994;11:290-294.

5. Miura K, Watanaba K, Maeda N, et al. Magnetic resonance imaging and positron emission tomography of band heterotopia. Brain Dev 1993;15:288-290.

6. Weschler, D. Weschler Intelligence Scales for Children-III, the Psychological Corporation, San Antonio, Texas,1971.

7. Harrison PL, Oakland. Adaptive Behavior Assessment System. The Psychological Corporation, San Antonio, Texas, 2000.

8. Cohen M. Children's Memory Scales. The Psychology Corporation, San Antonio, Texas 1997.

9. Sheslow D, Adams W. WRAML, Wide Range Assessment of Memory and Learning. Wilmington, Delaware: Wide Range Inc 1990.

10. Dunn LM, Dunn LM. Peabody Picture Vocabulary Test. Third Edition, American Guidance Service, Circle Pines, MN, 1997.

11. Wig E, Second W. Test of Language Competence. The Psychology Corporation, San Antonio, Texas 1989.

12. Weschler Individual Achievement Test. The Psychological Corporation, San Antonio, Texas, 1992.

13. Beery KE, Development Test of Visual-Motor Integration. Administration and Scoring Manual. Chicago: Fullett Publishing 1967.

14. Strupp JP. Stimulate: a GUI base fMRI analysis software package. Neuroimage 1996;3:S607.

15. Pinard J-M, Feydy A, Carlier R, et al. Functional MRI in double cortex: functionality of heteropia. Neurology 2000;54:15311533.

16. Spreer J, Martin P, Greenlee M, et al. Functional MRI in patients with band heterotopia. Neuroimage 2001;14:357-365.

17. Iannetti P, Spalice A, Raucci U, Perla F. Functional neuroradiological investigations in band heterotopia. Pediatr Neurol 2001;24:159-163.

18. Binder JR, Swanson SJ, Hammeke TA, et al. Determination of language dominance using functional MRI: a comparison with the Wada test. Neurology 1996;46:978-984.

19. FitzGerald D, Cosgrove G, Ronner S, et al. Location of language in the cortex: a comparison between functional MR imaging and electrocortical stimulation. AJNR AM J Neuroradiol 1997; 18:1529-1539.

20. Hertz-Pannier L, Gaillard WD, Mott SH, et al. Noninvasive assessment of language dominance in children and adolescents with functional MRI: a preliminary study. Neurology 1997; 48:1003-1012.

21. Yetkin F, Meuller W, Morris G, et al. Functional MR activation correlated with intraoperative cortical mapping. AJNR Am J Neuroradiol 1997;18:1311-1315.

22. Yousry T, Schmid UD, Jassoy AG, et al. Topography of the cortical motor hand area: prospective study of functional MR imaging and direct motor mapping at surgery. Radiology 1995;195:23-29. 